$\mathrm{XJM}$

$17,1 / 2$

\title{
Vice-Chancellor's message
}

It gives me immense pleasure to release Volume 17 (Issues 1 and 2) of Vilakshan-XIMB Journal of Management in association with Emerald Publishing Services (EPS). Henceforth, our journal will be published by EPS and all papers published in the journal will be freely made available online for better visibility.

Vilakshan has also recently been listed in UGC care, which signifies the quality of our journal. We are also targeting the listing of our journal in other indices to make our journal globally visible.

The pandemic situation has delayed the publication of the journal. However, along with this volume, we have simplified our process and we are expecting henceforth, we can publish our journal biannually systematically. I congratulate the Vilakshan team and so also the members of the EPS for bringing out this professionally designed and edited volume of Vilakshan.

This time we have received overwhelming responses from authors not only from India but also from other countries. Even the current volume carries six scholarly papers from renowned universities abroad. This indicates our global reach. Our editorial board is now represented by globally acknowledged academia. Our Associate Editors are also representing renowned Institutions of the country and abroad. Our reviewers also are wellacknowledged academia from different places.

Once again, I thank the entire editorial team for their sincere effort in the publication of Vilakshan.

Dr Fr. Antony R. Uvari, S.J. Vice-Chancellor 